\title{
THE EFFECTS OF INGOT COMPOSITION AND CONVERSION ON THE MECHANICAL PROPERTIES AND MICROSTRUCTURAL RESPONSE OF GTD-222
}

\author{
T. Banik, T. C. Deragon, and F. A. Schweizer \\ Special Metals Corporation \\ 4317 Middle Settlement Road \\ New Hartford, NY 13413
}

\begin{abstract}
The current trend in the aerospace industry toward larger and fewer engines pcr aircraft has resulted in new demands in gas turbine materials. GTD-222, a new alloy selected for combustion casings due to its excellent elevated temperature properties, was evaluated to determine the potential effects of chemistry and conventional processing techniques (VIM+VAR) on the alloy's microstructural response and mechanical properties. It was concluded that homogenization processing was nol a major contributor to improvements in elevated temperature properties. An increase in tensile properties was achieved with a solution heat treatment below the $\mathrm{M}_{23} \mathrm{C}_{6}$ solvus temperature. Stress rupture life and ductility were improved with increasing carbon content. In addition, increasing carbon content reduced the solidus and gamma-prime solvus temperatures and yielded a finer primary microstructure. It was concluded that reforging stock could be produced by VIM+VAR processing the alloy.
\end{abstract}

\section{Introduction}

The current trend in the aerospace industry toward larger and fewer engines per aircraft has resulted in new demands in gas turbine materials. The combustor case is one example of this trend. The new larger engines require materials which operate at higher temperatures and can be cost effectively produced into cases greater than one meter in diameter. Traditional alloys such as 718 and Waspaloy do not meet the temperature capability requirements. A cast alloy, GTD- $222^{1}$, was selected as a candidate for combustor case applications based on its elevated temperature properties. The challenge with GTD-222 focused on establishing cast/wrought production processes for the large ingot diameters necessary to produce billet sizes compatible with the requirements for large diameter seamless ring production.

GTD-222 was originally developed for cast gas turbine engine nozzle applications in 1989 . The alloy composition is similar to Waspaloy with some of the titanium replaced with niobium and tantalum. Initial cast wrought evaluations of GTD-222 were conducted on material produced by vacuum induction melting (VIM) plus electroslag remelting (ESR) to $300 \mathrm{~mm}$ diameter

\footnotetext{
GTD-222 is a patented nickel-based superalloy by General Electric Co. Superalloys 1996

Edited by R. D. Kissinger, D. J. Deye, D. L. Anton, A. D. Cetel, M. V. Nathal, T. M. Pollock, and D. A. Wood ford The Minerals, Metals \& Materials Society, 1996
}

ingots. The original properties generated from the VIM+ESR ingot demonstrated that GTD-222 alloy would meet the elevated properties required by GEAE design specifications. However, the ability to produce large diameter ingots of GTD-222, free of unacceptable macro and micro segregation, had to be demonstrated. Therefore, the next step was to determine the processing necessary to produce large diameter ingot products $(\geq$ $500 \mathrm{~mm}$ ) using a vacuum induction melt followed by vacuum arc remelting (VAR).

The purpose of the present investigation was to evaluate the potential effects of chemistry and conventional processing techniques in assessing the alloy's mechanical properties and microstructural response, specifically the effect of carbon, homogenization, and solution heat treatment temperatures. Modifications to the composition were focused on the carbon level. The GTD-222 alloy exhibits a primary carbide phase, $\mathrm{MC}$, and a chromium rich, $\mathrm{M}_{23} \mathrm{C}_{6}$, grain boundary carbide. The $\mathrm{MC}$ carbides precipitate during and shortly after solidification. The $\mathrm{M}_{23} \mathrm{C}_{6}$ carbides precipitate during aging as a semi-continuous film and negatively impact the stress rupture strength. The baseline composition of GTD-222 and the three compositional modifications evaluated are presented in Table I. Two different homogenization cycles and a no homogenization cycle were evaluated. The two solution temperatures evaluated were $1093^{\circ} \mathrm{C}$ and $1149^{\circ} \mathrm{C}$.

Table I The compositional modifications (in weight percent) were focused on carbon content.

\begin{tabular}{lcccc}
\hline & $\begin{array}{c}\text { Control } \\
\text { Heat }\end{array}$ & $\begin{array}{c}\text { Heat } \\
8377\end{array}$ & $\begin{array}{c}\text { Heat } \\
8376\end{array}$ & $\begin{array}{c}\text { Heat } \\
8422\end{array}$ \\
\hline $\mathrm{C}$ & 0.08 & 0.04 & 0.02 & 0.13 \\
$\mathrm{Cr}$ & 22.5 & 22.6 & 22.5 & 22.4 \\
$\mathrm{Co}$ & 19.1 & 19.0 & 19.1 & 19.1 \\
$\mathrm{~W}$ & 2.0 & 2.0 & 2.0 & 2.0 \\
$\mathrm{Nb}$ & 0.8 & 0.8 & 0.8 & 0.8 \\
$\mathrm{Ti}$ & 2.3 & 2.3 & 2.3 & 2.3 \\
$\mathrm{Al}$ & 1.2 & 1.2 & 1.3 & 1.2 \\
$\mathrm{~B}$ & 0.004 & 0.003 & 0.004 & 0.001 \\
$\mathrm{Zr}$ & 0.02 & 0.02 & 0.02 & 0.03 \\
$\mathrm{Ta}$ & 0.94 & 0.94 & 0.93 & 0.95 \\
$\mathrm{Ni}$ & Bal & Bal & Bal & Bal \\
\hline
\end{tabular}




\section{Experimentation}

Subscale heats were produced using a laboratory scale vacuum induction melting furnace. Four electrodes were produced and vacuum arc remelted to $152 \mathrm{~mm}$ diameter.

Each ingot product was sectioned to permit assessment of multiple homogenization procedures. Samples were exposed to homogenization cycles of $1178^{\circ} \mathrm{C}$ for 48 Hours, $1191^{\circ} \mathrm{C}$ for 27 Hours or no homogenization operation. A TA Instruments DSC 2910 Differential Thermal Analyzer was utilized to establish phase changes for each composition and to establish homogenization parameters. After homogenization, samples were rolled using a $75 \%$ reduction sequence. Solution anneal was performed at two temperatures, $1093^{\circ} \mathrm{C}$ or $1149^{\circ} \mathrm{C}$. All samples were followed by an age cycle of $802^{\circ} \mathrm{C}$ for 8 Hours prior to testing. Mechanical property evaluations were performed at $760^{\circ} \mathrm{C}$

The laboratory sized ingots restricted mechanical property evaluations to one sample per condition. Metallographic evaluations were performed to assess carbide distribution and grain size.

Stress rupture testing was performed on SATEC M3 or SATEC $C$ type stress rupture testing machines. Tensile testing was performed on an INSTRON 4208 tensile testing machine. Stress rupture and tensile testing furnaces incorporated standard laboratory cylindrical furnaces and proportional analog controllers for temperature control.

\section{Reisults and Discussion}

\section{Differential Thermal Analyses}

As indicated in Figure 1, the liquidus temperature remained approximately $1375^{\circ} \mathrm{C}$ for the different carbon compositions, whereas the solidus temperatures decreased with increasing carbon content The stability of the liquidus temperature was expected due to the overall chemical composition similarity. At low carbon contents $(0.02$ wt $\%)$, the solidus temperature was determined to be $1318^{\circ} \mathrm{C}$. At $0.13 \mathrm{wt} \%$ carbon, the solidus temperature decreased to $1300^{\circ} \mathrm{C}$. The lower solidus

\section{Liquidus, Solidus Temperatures}

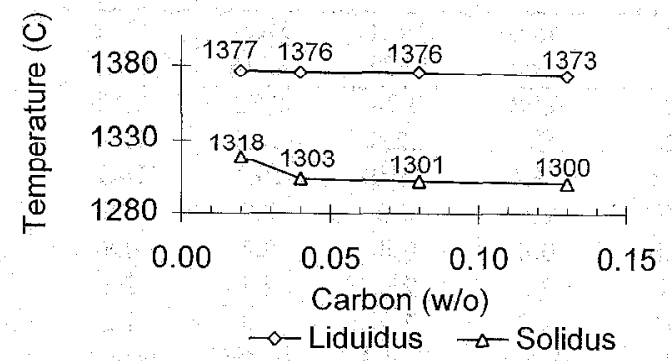

Figure 1. Increasing carbon weight percent did not affect the liquidus temperature but resulted in a decreasing solidus temperature. temperature at increasing carbon levels is expected since carbon is a melting point depressant.

The GTD-222 alloy is a gamma-prime strengthened alloy. The gamma-prime solvus start and finish temperatures decreased with increasing carbon content, as indicated in Figure 2. The decrease in gamma-prime solvus temperature is due to the increase in primary carbides depleting the matrix of titanium, niobium and tantalum.

\section{Gamma Prime Solvus Temperatures}

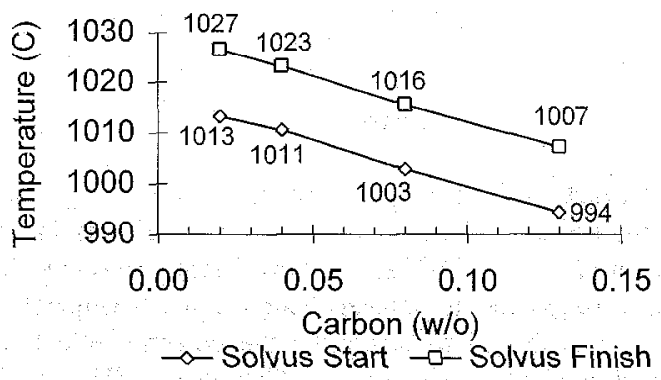

Figure 2: Increased carbon weight percent decreased gammaprime start and finish solvus temperatures.

\section{Mechanical Properties}

Homogenization. The test data revealed no differences in mechanical properties among the various homogenization cycles. The yield and tensile strengths were generally $690 \mathrm{MPa}$ and 900 $\mathrm{MPa}$, respectively. Tensile ductility ranged from $8 \%$ to $20 \%$ for elongation in a $4 \mathrm{D}$ sample and $12 \%$ to $22 \%$ for reduction of area. A stress rupture life of approximately 45 hours and $2 \%$ to $20 \%$ clongation in a $4 \mathrm{D}$ testing section at $760^{\circ} \mathrm{C}$ and $462 \mathrm{MPa}$ load were typical for all carbon compositions. The similarity of the mechanical properties for the homogenization trials may be the result of the laboratory scale ingot size. The faster cooling rate of the smaller, laboratory-size ingots (152 $\mathrm{mm}$ diameter) permit solidification with minimal segregation, whereas larger, production sized ingots ( $>300 \mathrm{~mm}$ diameter) experience slower solidification of alloy lean areas resulting in increased segregation of alloy rich areas.

Solution Temperature. A graphical summary of the yield and tensile strengths for the $1093^{\circ} \mathrm{C}$ and $1149^{\circ} \mathrm{C}$ solution temperatures is presented in Figure 3a. Similarly, the tensile ductility results are presented in Figure $3 \mathrm{~b}$ for the two solution temperatures. The anneal temperature $\left(1093^{\circ} \mathrm{C}\right)$ generally exhibited slightly higher yield and tensile strengths for the 0.02 , 0.04 and 0.08 wt \% carbon composition samples when compared to the results for the $1149^{\circ} \mathrm{C}$ solution treated material. The tensile properties for the 0.13 wt \% carbon composition material was unaffected by the solution temperature Tensile ductility was generally lower for all compositions with the $103^{\circ} \mathrm{C}$ solution temperature compared to the $1149^{\circ} \mathrm{C}$ solutioned samples.

The stress rupture life and elongation results for the $1093^{\circ} \mathrm{C}$ and $1149^{\circ} \mathrm{C}$ solution temperatures are presented in Figure $3 \mathrm{c}$. The decrease in the stress rupture life between the $1093^{\circ} \mathrm{C}$ and 
$760 \mathrm{C}$ Tensile Test

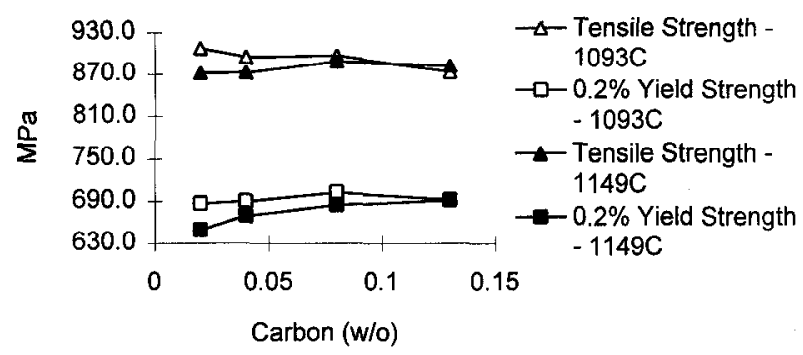

$3 a$

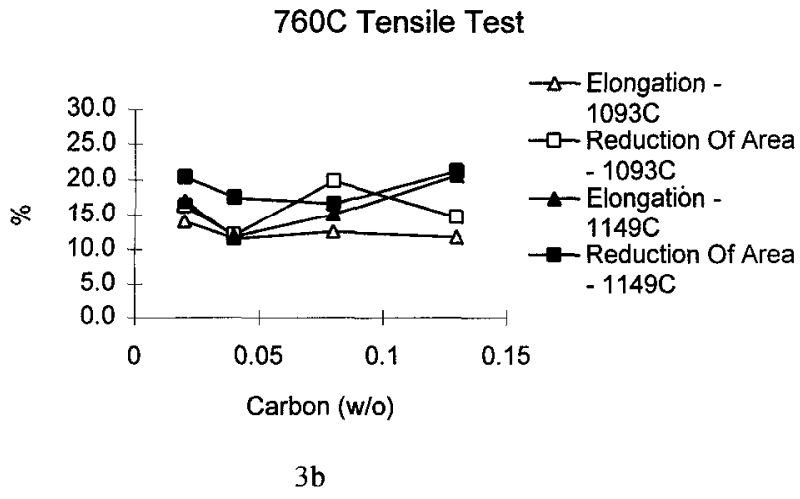

760C, 462 MPa Stress Rupture

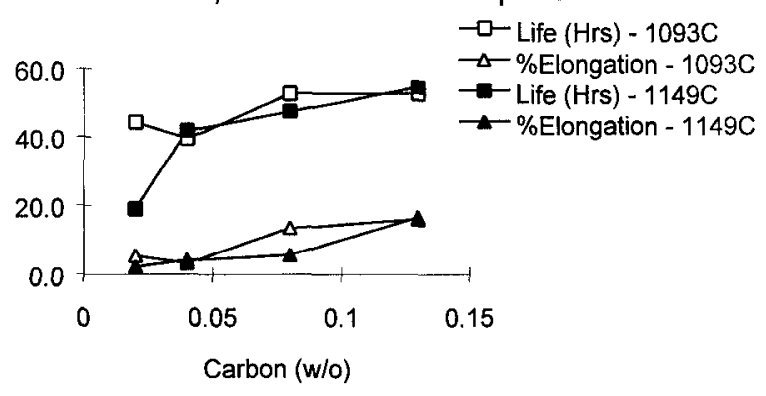

$3 \mathrm{c}$

Figure 3: a) The samples exposed to the $1093^{\circ} \mathrm{C}$ solution temperature generally exhibited increased yield and tensile strengths. Carbon content did not appear to significantly affect yield and tensile strengths.

b) The samples exposed to the $1093^{\circ} \mathrm{C}$ solution temperature generally exhibited lower tensile ductility. Carbon content did not appear to significantly affect tensile ductility.

c) The samples exposed to the $1093^{\circ} \mathrm{C}$ solution temperature did not appear to significantly affect stress rupture life and ductility. Carbon content appears to affect stress rupture life and ductility positively. $1149^{\circ} \mathrm{C}$ solution temperatures for the $0.02 \mathrm{wt} \%$ carbon composition may be due to an increase in $\mathrm{M}_{23} \mathrm{C}_{6}$ continuity with increasing grain size at the higher solution temperature. Stress rupture life and ductility of higher carbon levels (>0.02 wt \%) appeared unaffected by solution temperature.

Carbon Level. When comparing mechanical property results from the varying carbon levels, the tensile properties appeared unaffected by carbon composition, as indicated in Figures $3 a$ and 3b. An increase in rupture life and ductility appears evident with increasing carbon content (Figures 3c), probably due to the fincr grain size created by the increased primary carbides. While the increased carbon content provides improved control of the grain size during heat treatment, with higher carbon levels, the propensity of carbides and the magnitude of stringer formation also increases. A trade-off between grain size control and stringer formation subsequently results.

\section{Microstructure}

The carbide distribution, as presented in Figure 4, significantly increased with increasing carbon content. The primary carbides consisted principally of niobium, tantalum and titanium. In production scale VIM+VAR processed material, increased carbon content has resulted in a coarse stringer-like carbide distribution.

The grain size of the samples correlated directly with the carbon content at both solution heat treatments. As indicated in Figure 5 , an increase in carbon content resulted in a finer primary grain structure by inhibiting grain growth. The increase in grain size was most dramatic at the lowest carbon content of $0.02 \mathrm{wt} \%$. Grain coarsening was the greatest for the $0.02 \mathrm{wt} \%$ carbon composition with increasing solution treatment temperatures from $1093^{\circ} \mathrm{C}$ to $1177^{\circ} \mathrm{C}$. The 0.02 wt \% sample increased in grain size from ASTM 4 to ASTM 00, while the grain size for the $0.13 \mathrm{wt} \%$ sample remained relatively constant at an ASTM 6.5 to 7 .

\section{Conclusion}

The subscale investigations into GTD-222 processing revealed:

- The carbon content did not significantly affect the liquidus temperature, but gradually reduced the solidus and gamma. prime solvus temperatures with increasing carbon content.

- On subscale ingots, homogenization was not a major contributor to improvements in elevated temperature tensile and stress rupture strength.

- The lower solution temperature, $1093^{\circ} \mathrm{C}$, exhibited slightly increased yield and tensile strengths and slightly decreased ductility.

- For the higher $(>0.02$ wt \%) carbon compositions, solution temperature did not appear to have a significant effect on stress rupture properties.

- At 0.02 wt $\%$ carbon the $1093^{\circ} \mathrm{C}$ solution temperature produced significantly increased life compared to the $1149^{\circ} \mathrm{C}$ solution. 


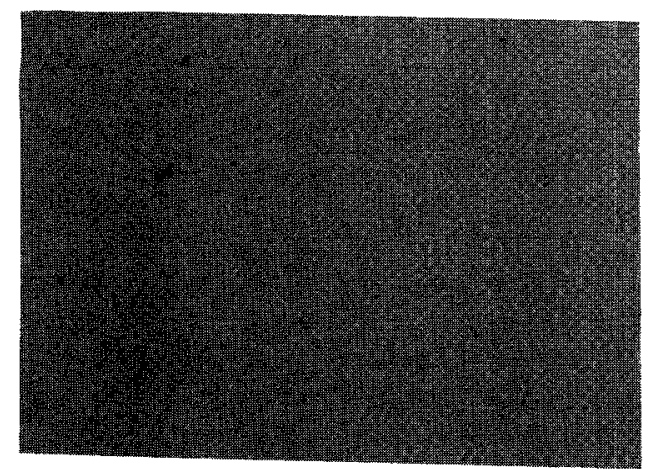

$4 \mathrm{a}$

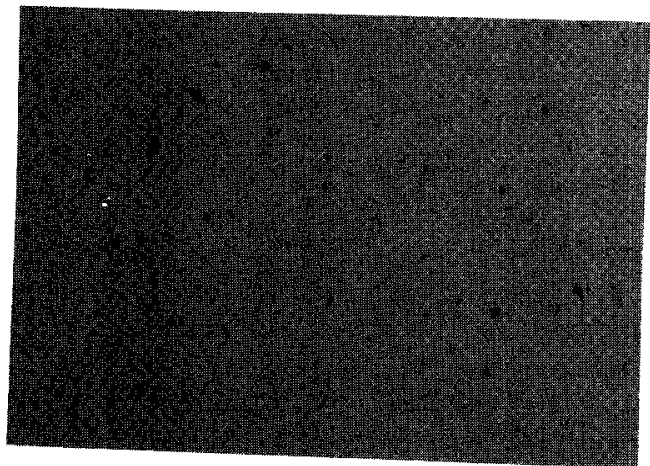

$4 \mathrm{c}$

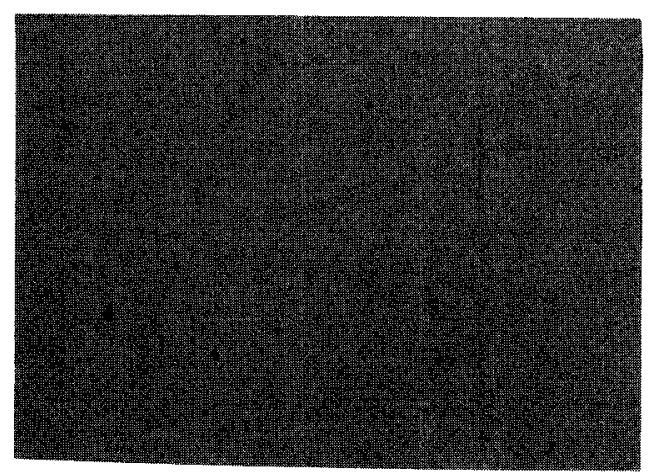

$4 \mathrm{~b}$

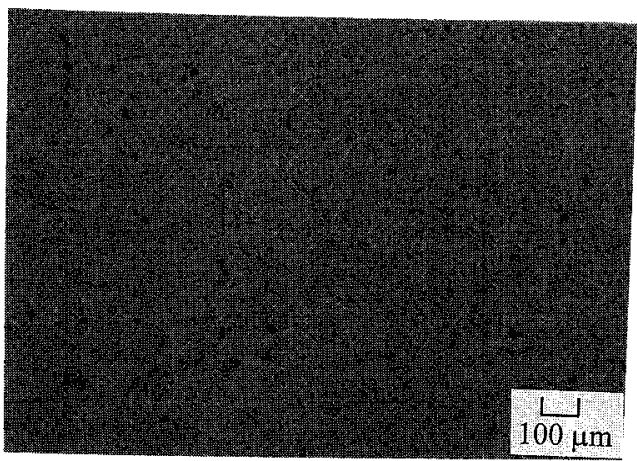

$4 d$

Figure 4: The MC distribution of VAR ingot material increased considerably with increasing carbon content. a) 0.02 wt $\%$ Carbon. b) 0.04 wt \% Carbon. c) 0.08 wt \% Carbon. d) 0.13 wt \% Carbon.
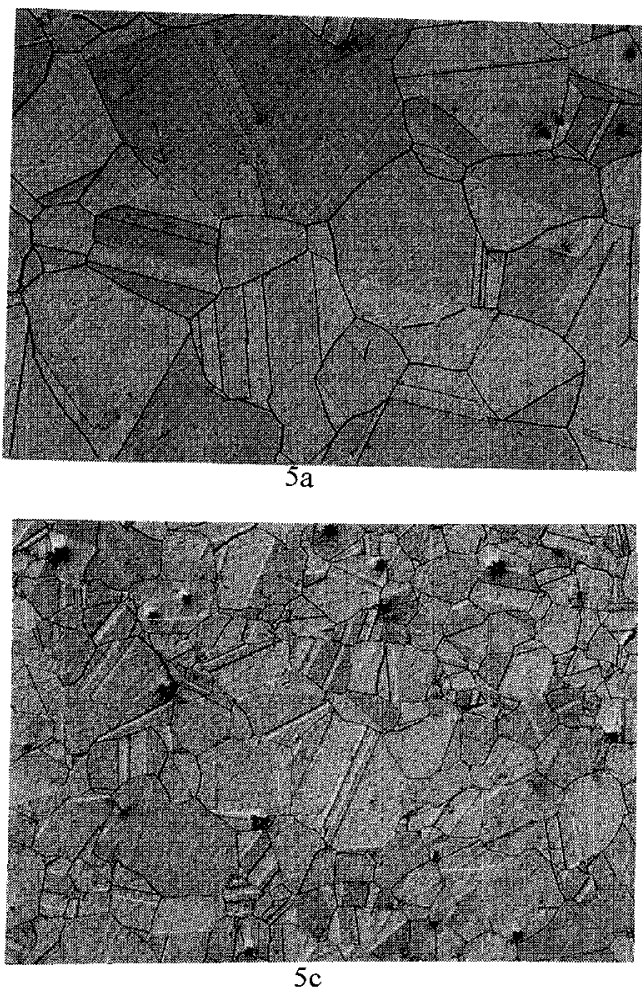

Figure 5: The grain size after roll-down processing and $1093^{\circ} \mathrm{C}$ anneal and age heat treatment was finer with increasing carbon content due to the increased MC frequency. a) $0.02 \mathrm{wt} \%$ Carbon. b) $0.04 \mathrm{wt} \%$ Carbon. c) $0.08 \mathrm{wt} \%$ Carbon. d) $0.13 \mathrm{wt} \%$ Carbon.

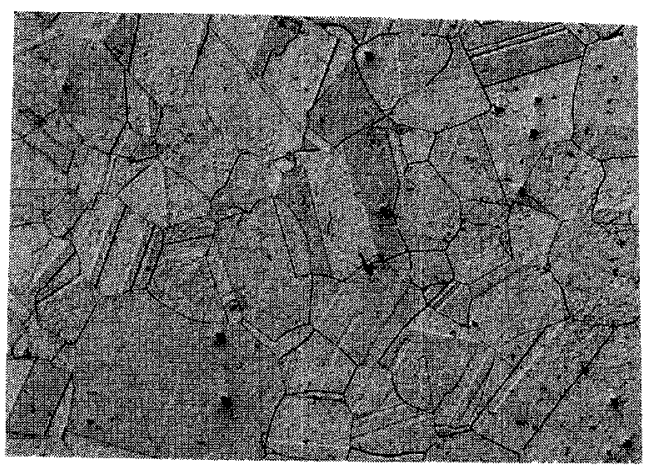

$5 \mathrm{~b}$

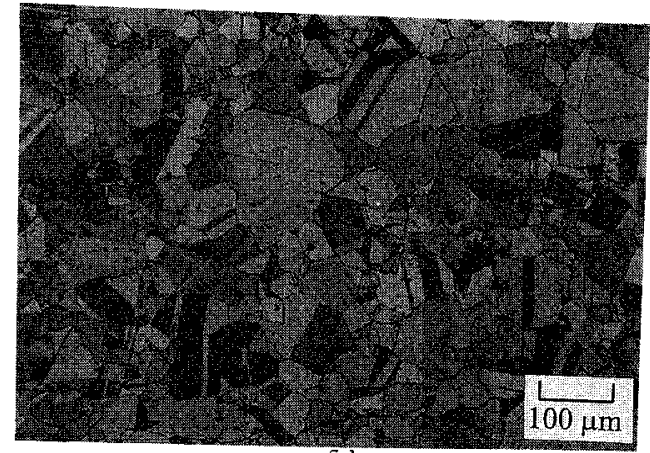

$5 d$ 


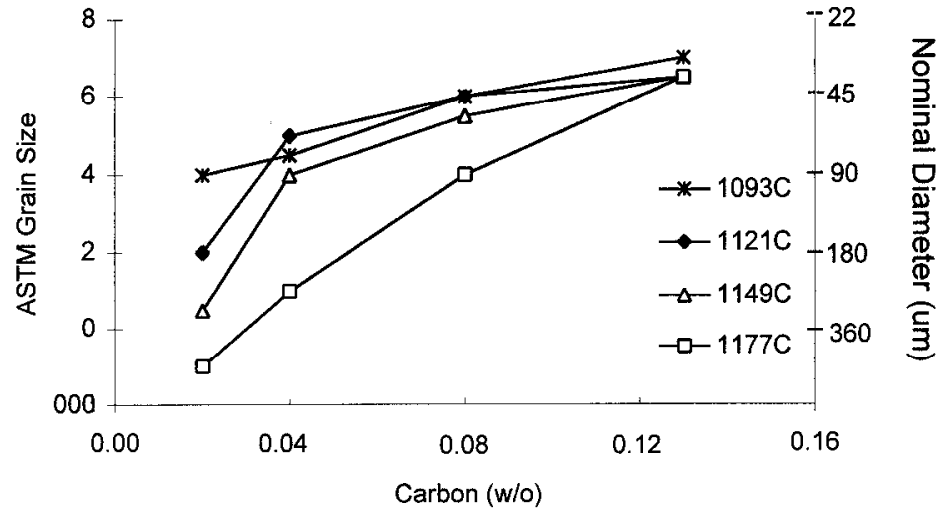

Figure 6: The grain size decreased with increasing carbon content and solution temperature.

- Increasing carbon levels did not have a significant influence on the tensile properties.

- Increasing the carbon content from $0.02 \mathrm{wt} \%$ to $0.13 \mathrm{wt} \%$ resulted in a finer primary microstructure. Heat treatments through the $1149^{\circ} \mathrm{C}$ solution temperature resulted in grain coarsening of 0 to 4 ASTM values. Grain coarsening occurred at a higher rate with lower carbon compositions.
Subscale investigations on GTD-222 indicated that VIM+VAR processing can be utilized to meet the property requirements necessary for the advanced engines. Subsequent full-scale material has been produced and confirmed the initial results.

\section{Acknowledgments}

The authors wish to express their thanks to Lance Myers for his metallographic support. 